\title{
PEMANFAATAN LIMBAH CANGKANG KERANG MUTIARA (PINCTADA MAXIMA) SEBAGAI SUMBER HIDROKSIAPATIT
}

\author{
Susi Rahayu*, Dian W. Kurniawidi, Abdul Gani \\ Laboratorium Fisika Material FMIPA Universitas Mataram \\ *Email: susirahayu@unram.ac.id
}

\begin{abstract}
Pearl shells (pinctada maxima) are the superior commodities in West Nusa Tenggara Province. The shellfish is utilized as a producer of pearls while the waste of pearl shells has not been widely used by the community. Main composition of fhe pearl shells is calcium. CaO content was tested using AAS and obtained $\mathrm{CaO}$ in shells as much as 52.23\%. CaO is used as a source of hydroxyapatite (HAp). Shellfish powder is synthesized with H3PO4 compound. Synthesis is conducted by precipitation method. Synthesis results were analyzed utilizing XRD and FTIR. From the examination, HAp compounds were identified. Group of PO43, CO32, and OH are constituent groups of HAp compounds. Moreover, another calcium phosphate is formed namely TCP. This HAp compound has a maximum crystallinity of $78.33 \%$ at an angle of $77.18^{\circ}$. The smallest HAp particle size at an angle of $31.92^{\circ}$ is $1.4 \mu \mathrm{m}$. The degree of high crystallinity is influenced by high intensity and a wide FWHM. Meanwhile, the small molecule size is acquired on a wide FWHM with a small Bragg angle position.
\end{abstract}

Keywords: Pinctada Maxima, Synthesis, Hidroksiapatite

\section{PENDAHULUAN}

Perairan di Nusa Tenggara Barat (NTB) memiliki potensi dalam membudidayakan kerang mutiara (pinctada maxima). Kerang mutiara merupakan komoditas unggulan NTB dimana setiap tahun menghasilkan limbah cangkang kerang sebanyak $600 \mathrm{~kg}$. Limbah ini belum banyak dimanfaatkan oleh masyarakat sekitar. Secara umum komposisi dari cangkang kerang terdiri dari $\mathrm{Ca}, \mathrm{Mg}, \mathrm{Na}, \mathrm{P}$, dan mineral lain berupa $\mathrm{Fe}, \mathrm{Cu}, \mathrm{Ni}, \mathrm{B}, \mathrm{Zn}$, serta Si. Kandungan kalsium karbonat pada cangkang kerang ini merupakan sumber kalsium yang dapat dimanfaatkan sebagai Hidroksiapatit (Khairil, 2012)

Hidroksiapatit (HAp) merupakan senyawa yang mengandung ion kalsium $\left(\mathrm{Ca}^{2+}\right)$ yang mengubah ion logam beracun dan menyerap unsur kimia organik dalam tubuh (Dahlan, 2013). Senyawa ini banyak dimanfaatkan sebagai tempat tumbuh kembangnya jaringan apabila ada jaringan yang rusak. Setiap tahun, kebutuhan senyawa ini semakin meningkat terutama dalam bidang kedokteran seperti tulang, gigi, kosmetik, dan kultur jaringan. Sehingga untuk memperoleh senyawa HAp pada penelitian ini dilakukan sintesis HAp dari limbah cangkang kerang mutiara.

Sintesis HAp dapat dilakukan dengan beberapa metode:

a) Metode basah (presipitasi), menggunakan reaksi cairan.

b) Metode kering, menggunakan reaksi padat.

c) Metode hidrotermal, menggunakan reaksi hidrotermal.

d) Metode alkoksida, menggunakan reaksi hidrolisa

e) Metode fluks, menggunakan reaksi peleburan garam.

Metode lain yang biasa digunakan yaitu sol gel. Metode ini dapat menghasilkan serbuk HAp dengan ukuran butir yang relative homogen dan derajat kristalinitas tinggi (Sunarso et al, 2013 dan Gergely et al, 2009).

Berbagai metode sintesis dengan beberapa jenis cangkang kerang telah banyak dilakukan. Sintesis HAp dari cangkang kerang kepah menggunakan metode presipitasi (kimia basah-). Cangkang kerang 
darah direaksikan dengan diamonium hydrogen fosfat menghasilkan HAp $71 \%$ dengan waktu pengadukan 90 menit (Ningsih et al, 2014). Cangkang kerang ranga disintesis dengan metode presipitasi pada suhu $80^{\circ}$ dan sintering suhu $900^{\circ}$ menghasilkan HAp ( Balgies et al, 2011). Metode hidrotermal digunakan untuk mensitesis HAp dari cangkang kerang lokan. Dari penelitian ini diperoleh hasil terbaik HAp pada lama waktu reaksi 20 jam dan suhu $140^{\circ} \mathrm{C}$ (Arrafiqie et al, 2016). Dari penelitian yang telah dilakukan, komposisi mineral kulit kerang dari 3 sumber yang berbeda adalah sama untuk semua sampel. Gabungan kalsium karbonat dan karbon terdiri lebih dari $98,7 \%$ dari total kandungan mineral. $\mathrm{Mg}, \mathrm{Na}, \mathrm{P}, \mathrm{K}$ dan lain-lain $(\mathrm{Fe}, \mathrm{Cu}$, $\mathrm{Ni}, \mathrm{B}, \mathrm{Zn}$ dan Si) terdiri sekitar 1,3\%. Komposisi mineral kulit kerang adalah $98,7 \% \mathrm{Ca}, 0,05 \% \mathrm{Mg}, \mathrm{Na} 0,9 \%, 0,02 \% \mathrm{P}$ dan 0,2\% lainnya. Kandungan kalsium karbonat pada kulit kerang merupakan sumber kalsium yang dapat digunakan sebagai bahan sintesis hidroksiapatit (Khairil, 2012).

\section{METODE PENELITIAN}

Hidroksiapatit (HAp) dari limbah cangkang kerang mutiara diperoleh melalui metode presipitasi. Adapun tahapan metode penelitian yang dilakukan yaitu :

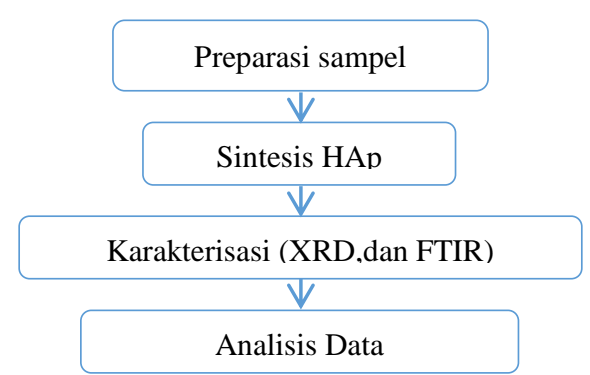

Gambar 1. Tahapan penelitian

Preparasi awal cangkang kerang mutiara dilakukan dengan membersihkan cangkang. Cangkang kerang disikat hingga bersih. Kemudian cangkang kerang dikeringkan dengan memanfaatkan panas matahari. Cangkang yang sudah kering dipecah menjadi ukuran lebih kecil dan di furnace selama 2 jam. Hasil sampel yang telah di furnace dihaluskan menggunakan mortar sehingga diperoleh serbuk cangkang kerang mutiara. Serbuk di uji menggunakan AAS untuk memperoleh kandunga $\mathrm{CaO}$.

Serbuk cangkang kerang mutiara disintesis menggunakan senyawa $\mathrm{H}_{3} \mathrm{PO}_{4}$ dengan suhu $100^{\circ} \mathrm{C}$. Larutan didiamkan selama 24 jam untuk memperoleh endapan hidroksiapatit. Endapan ini dikalsinasi pada suhu $800^{\circ} \mathrm{C}$. Hasil sintesis dikarakterisasi menggunakan XRD dan FTIR.

Melalui karakterisasi XRD diperoleh struktur kristal, perubahan fasa, ukuran partikel, dan derajat kristalinitas. Perubahan fasa yang terjadi dapat ditinjau melalui pembentukan puncak-puncak yang terbentuk. Puncak-puncak sampel dibandingkan dengan database JCPDS 090432 untuk fasa HAp dan JCPDS 09-0169 untuk fasa TCP (Tricalcium Phosphate) sebagai dasar penentuan fasa. Derajat kekristalan senyawa dapat diperoleh melalui persamaan :

kristalinitas $=\frac{\text { Fraksi luas kristal }}{\text { fraksi } L \text { kristal }+ \text { fraksi } L \text { amorf }}$

Fraksi luas Kristal merupakan perkalian B dengan intensitas. B adalah FWHM (full width at half maximum) dari puncak. Nilai B dapat diperoleh melalui persamaan:

$$
B=\frac{1}{2}\left(2 \theta_{2}-2 \theta_{1}\right)
$$

Ukuran partikel dapat diperoleh melalui persamaan Scherer:

$$
D=\frac{k \lambda}{B \cos \theta}
$$

ukuran partikel dilambangkan dengan D, lebar FWHM dilambangkan dengan B, sedangakan $\lambda$ dan $\theta$ secara berturut-turut didefinisikan sebagai panjang gelombang dan sudut bragg pada puncak difraksi.

Karakterisasi FTIR dimanfaatkan untuk mengidentifikasi gugus kompleks pada senyawa HAp. Metode ini dapat 
mendeteksi energy yang diserap oleh setiap gugus fungsi yang bergetar. Jumlah energy yang diserap dapat menentukan senyawa yang terkandung didalam bahan (Road, 2001).

\section{HASIL DAN PEMBAHASAN}

Cangkang kerang mutiara ditumbuk menggunakan mortar hingga menghasilkan serbuk cangkang kerang. Serbuk ini diuji kadar $\mathrm{CaO}$ menggunakan AAS. Dari hasil uji diperoleh kandungan $\mathrm{CaO}$ pada cangkang kerang mutiara sebesar 52,23\%.

Serbuk disintesis menghasilkan endapan senyawa HAp. Endapan ini dikalsinasi sehingga menghasilkan serbuk berwarna putih dan halus (Gambar 2). Warna putih pada sampel akibat adanya kandungan kalsium pada senyawa. Ukuran sampel yang halus disebabkan adanya proses kalsinasi dengan temperature tinggi sehingga mengakibatkan perubahan ukuran partikel. Proses kalsinasi dilakukan untuk menghilangkan unsur $\mathrm{CO}_{2}$ pada sampel.

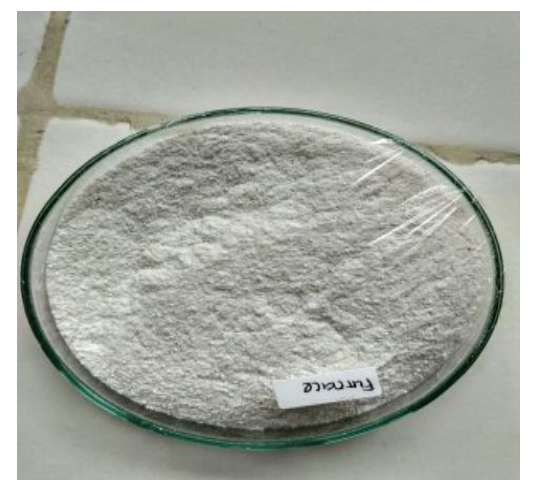

Gambar 2. Serbuk Senyawa HAp

Secara kualitatif kandungan HAp dapat diprediksi menggunakan data FTIR. Berdasarkan data FTIR dapat diketahui HAp dari gugus fungsi yang terbentuk. Gugus penyusun senyawa HAp terdiri dari gugus $\mathrm{PO}_{4}{ }^{3-}$, gugus $\mathrm{CO}_{3}{ }^{2-}$, dan gugus $\mathrm{OH}^{-}$.

Gugus fungsi yang teramati pada HAp komersial pada gugus fosfat $\left(\mathrm{PO}_{4}{ }^{3-}\right)$ pada bilangan gelombang 1156-1000 $\mathrm{cm}^{-}{ }^{1}$, $960 \mathrm{~cm}^{-1}, 600-560 \mathrm{~cm}^{-1}, 460 \mathrm{~cm}^{-1}$, gugus hidroksil $\left(\mathrm{OH}^{-}\right)$pada bilangan gelombang
3700-2600 cm- ${ }^{1}, 630 \mathrm{~cm}^{-1}$, dan gugus karbonat $\left(\mathrm{CO}_{3}{ }^{2-}\right)$ pada bilangan gelombang $1640 \mathrm{~cm}^{-1}, 1460 \mathrm{~cm}^{-1}, 1450 \mathrm{~cm}^{-}{ }^{1}, 1418 \mathrm{~cm}-$ 1, dan $1384 \mathrm{~cm}^{-1}$ (Berzina-Cimdia \& Borodajenko, 2012) . Gugus $\mathrm{PO}_{4}{ }^{3-}$ dan $\mathrm{OH}^{-}$ yang tajam mengindikasikan intensitas absorpsi yang lebih tinggi. Semakin tinggi intensitas absorbsi, semakin banyak kandungan $\mathrm{PO}_{4}{ }^{3-}$ dan $\mathrm{OH}^{-}$(Walendra, 2012).

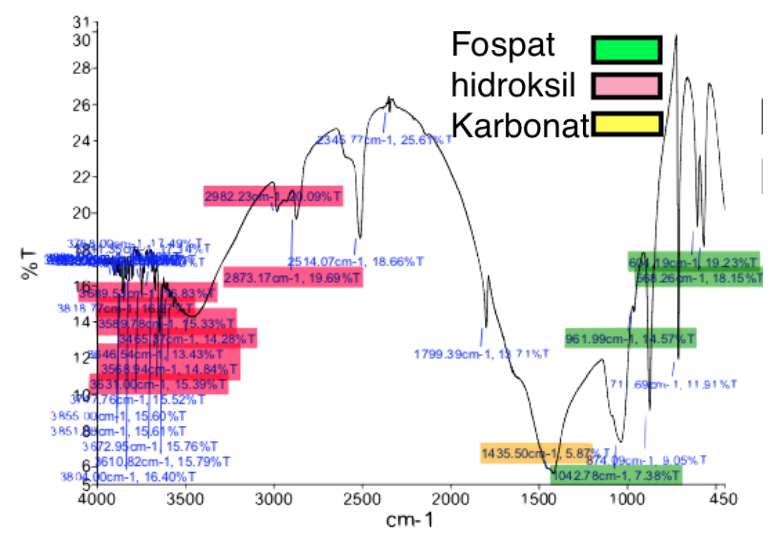

Gambar 3. Hasil analisis FTIR serbuk cangkang kerang mutiara

Puncak $\mathrm{PO}_{4}{ }^{3-}$ yang tajam mengindikasikan pertumbuhan kristalinitas yang semakin baik. Kristalinitas yang baik sebanding dengan kualitas HAp yang baik. Gugus $\mathrm{PO}_{4}{ }^{3-}$ memiliki 4 mode vibrasi yaitu vibrasi simetri stretching, simetri bending, asimetri stetching, dan asimetri bending. Dari hasil penelitian diperoleh tiga mode vibrasi yang terjadi yaitu vibrasi simetri bending $\left(961,99 \mathrm{~cm}^{-1}\right)$, vibrasi asimetri stetching $\left(1042,78 \mathrm{~cm}^{-1}\right)$, dan vibrasi asimetri bending $\left(604,19 \mathrm{~cm}^{-1}\right.$ dan 568,26 $\mathrm{cm}^{-1}$ ). Sehingga dari analisis FTIR muncul gugus-gugus fungsi pembentuk senyawa HAp.

Analisis XRD dimanfaatkan untuk mendukung analisis FTIR yang dilakukan.. Dari hasil karakteriasi XRD diperoleh grafik perbandingan sampel dengan database JCPDS untuk HAp. 


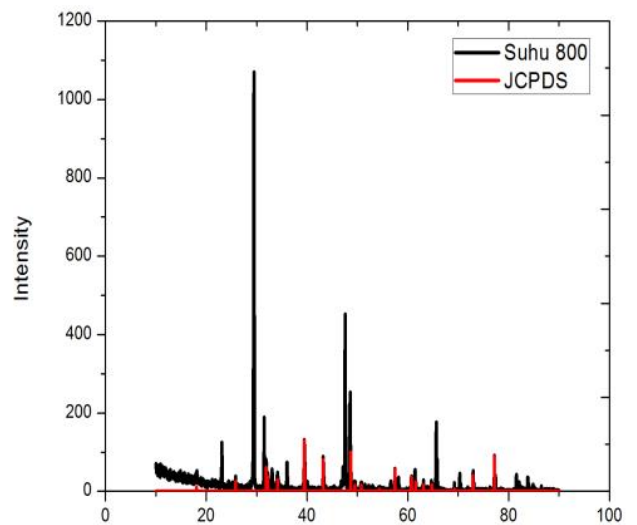

Gambar 4. Perbandingan pola difraksi HAp dari cangkang kerang mutiara dengan database JCPDS.

Dari grafik diatas secara kualitatif terlihat adanya kemiripan bentuk grafik sampel dengan database HAp. Beberapa puncak yang terbentuk pada sampel mengikuti puncak HAp pada database. Namun beberapa puncak HAp yang muncul memiliki intensitas dan FWHM yang berbeda dengan database. Perbedaan ini akan mempengaruhi kualitas HAp yang terbentuk baik dari segi derajat kristalinitas maupun ukuran partikelnya sesuai dengan persamaan 1 dan 3.

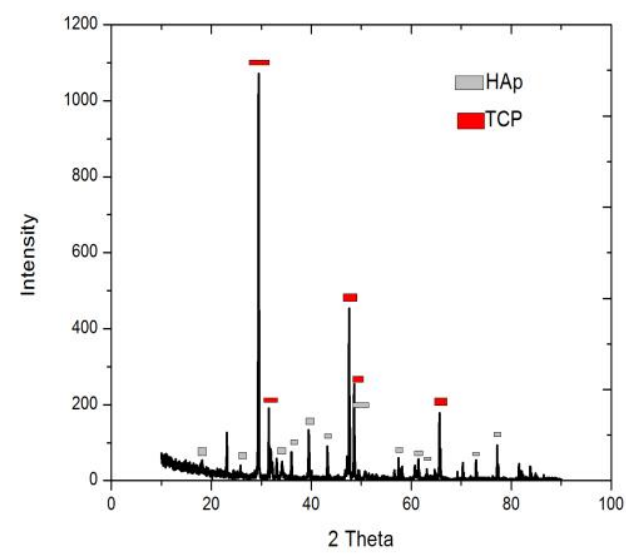

Gambar 5. Analisis fasa berdasarkan database

Secara kuantitatif HAp yang diperoleh dapat ditinjau dari perubahan fasa, derajat kristalinitas, dan ukuran partikel HAp. Perubahan fasa yang terbentuk ditinjau berdasarkan database JCPDS. Berdasarkan database terdapat senyawa kalsium fosfat lain yang terbentuk yaitu TCP (Gambar 5).

Dari pola XRD, jumlah senyawa HAp sekitar 19 puncak dan TCP sekitar 11 puncak. Terbentuknya TCP akibat proses sintesis yang dilakukan. Senyawa ini dapat terbentuk pada proses pencampuran ataupun pemanasan. Dari 19 puncak HAp yang terbentuk, terdapat 7 puncak yang memiliki intesitas tinggi (Tabel 1)

Tabel 1. Puncak Bragg dan intensitas HAp pada Sampel

\begin{tabular}{cc}
\hline $2 \theta$ & Intensitas \\
\hline 31,92 & 62,36 \\
\hline 39,47 & 129,42 \\
\hline 43,21 & 81,79 \\
\hline 48,70 & 100,16 \\
\hline 57,45 & 56,72 \\
\hline 72,94 & 40,37 \\
\hline 77,18 & 89,63 \\
\hline
\end{tabular}

Dari ketujuh puncak tertinggi HAp, dapat teranalisis derajat kristalinitasnya. Derajat kristalinitas dapat ditentukan menggunakan persamaan 1 (tabel 2).

Tabel 2. Derajat kristalinitas puncak HAp

\begin{tabular}{cccc}
\hline $2 \theta\left({ }^{\circ}\right)$ & $\mathrm{B}\left({ }^{\circ}\right)$ & $\begin{array}{c}\text { Intensitas } \\
(\mathrm{Cd})\end{array}$ & Kristalinitas $(\%)$ \\
\hline 31,92 & 0,12 & 62,36 & 77,81 \\
\hline 39,46 & 0,06 & 129,47 & 60,92 \\
\hline 43,2 & 0,06 & 81,79 & 74,52 \\
\hline 48,7 & 0,07 & 100,16 & 52,59 \\
\hline 57,45 & 0,10 & 56,72 & 60,40 \\
\hline 72,94 & 0,10 & 40,37 & 75,83 \\
\hline 77,18 & 0,10 & 89,63 & 78,33 \\
\hline
\end{tabular}

Derajat kristalinitas tertinggi berada pada sudut bragg $77,18^{\circ}$ yaitu $78,33 \%$. Derajat kristalinitas dari pola difraksi tersebut dipengaruhi oleh intensitas dan FWHM puncak difraksi (persamaan 1). Dari hasil penelitian yang dilakukan, semakin tinggi intensitas kristal belum tentu derajat kristalinitas akan semakin tinggi. Namun hal ini sangat dipengaruhi oleh nilai lebar FWHM puncak difraksi. 
Puncak difraksi tertinggi berada pada sudut $39,47^{\circ}$ dengan intensitas 129,42 (Cd). Pada puncak ini ukuran partikel HAp 2,86 $\mu \mathrm{m}$ (tabel 3). Ukuran partikel terkecil berada pada sudut bragg $31,92^{\circ}$ yaitu $1,40 \mu \mathrm{m}$. Pada sudut ini nilai intensitas dan derajat kristalinitas secara berturut-turut $62,36 \mathrm{Cd}$ dan $77,81 \%$, serta memiliki nilai FWHM yang paling tinggi 0,12 . Sehingga ukuran partikel sangat dipengaruhi oleh FWHM. Hal ini sesuai dengan persamaan Scherer.

Tabel 3. Ukuran partikel pada puncak difraksi HAp

\begin{tabular}{ccc}
\hline $2 \theta\left(^{\circ}\right)$ & Kristalinitas $(\%)$ & $\mathrm{D}(\mu \mathrm{m})$ \\
\hline 31,92 & 77,81 & 1,40 \\
\hline 39,46 & 60,91 & 2,86 \\
\hline 43,2 & 74,52 & 2,90 \\
\hline 48,7 & 52,59 & 2,41 \\
\hline 57,45 & 60,40 & 1,89 \\
\hline 72,94 & 75,83 & 2,06 \\
\hline 77,18 & 78,33 & 2,30 \\
\hline
\end{tabular}

Dari tabel diatas, kristalinitas dan intensitas tinggi tidak mempengaruhi ukuran partikel. Namun ukuran partikel sangat dipengaruhi oleh FWHM dan posisi sudut bragg .

Oleh karena itu untuk memperoleh kekristalan yang baik dan ukuran partikel kecil, hal yang perlu diperhatikan dalam grafik pola difraksi yaitu memiliki intensitas tinggi dengan FWHM lebar. Selain itu posisi sudut Bragg juga mempengaruhi nilai kekristalan material

\section{PENUTUP}

Hidroksiapatit dapat diperoleh dari cangkang kerang mutiara melalui sintesis. Secara kualitatif dari hasil analisis XRD dan FTIR menunjukkan adanya kandungan HAp pada serbuk cangkang kerang mutiara. Grafik XRD HAp dari cangkang kerang mutiara memiliki pola kemunculan puncak yang besesuaian dengan database. Dari analisis FTIR teridentifikasi munculnya gugus penyusun $\mathrm{HAp}$ yaitu gugus $\mathrm{PO}_{4}{ }^{3-}$, gugus $\mathrm{CO}_{3}{ }^{2-}$, dan gugus $\mathrm{OH}^{-}$. Sedangkan secara kuantitatif hasil analisis XRD teridentifikasi munculnya fasa senyawa HAp dan TCP. Senyawa TCP muncul akibat proses sintesis yang dilakukan. Senyawa HAp yang diperoleh memiliki derajat kristalinitas tertinggi pada sudut bragg $77,18^{\circ}$ yaitu $78,33 \%$ dan ukuran partikel terkecil berada pada sudut bragg $31,92^{\circ}$ yaitu 1,40 $\mu \mathrm{m}$. Derajat kristalinitas yang baik diperoleh pada intensitas yang tinggi dengan FWHM yang lebar. Sedangkan ukuran partikel yang kecil diperoleh pada FWHM yang lebar dengan posisi sudut bragg yang kecil.

\section{UCAPAN TERIMAKASIH}

Penelitian ini di danai oleh sumber dana DIPA BLU Universitas Mataram dengan nomor kontrak 1376.V/UN18.L1/PP/2018.

\section{REFERENSI}

Arrafiqie, M. F., \& Azis, Y. 2016. Sintesis Hidroksiapatit dari Limbah Kulit Kerang Lokan (Geloina Expansa) dengan Metode Hidrothermal. Jurnal Online Mahasiswa Fakultas Teknik Universitas Riau, 3(1), 1-8.

Balgies, S. U. D., \& Dahlan, K. 2011. Sintesis dan Karakterisasi Hidroksiapatit Menggunakan Analisis X-Ray Diffraction. In Prosiding Seminar Nasional Hamburan Neutron dan Sinar-X ke (Vol. 8). Serpong.

Berzina-Cimdina, L., \& Borodajenko, N. 2012. Research of calcium phosphates using Fourier transform infrared spectroscopy. In Infrared Spectroscopy-Materials Science, Engineering and Technology InTech. 123-148.

Dahlan, K. 2013. Potensi Kerang Ranga Sebagai Sumber Kalsium Dalam Sintesis Biomaterial Subtitusi Tulang. Prosiding Semirata FMIPA, Universitas Lampung, 
Gergely, G., Wéber, F., Lukács, I., Tóth, A. L., Horváth, Z. E., Mihály, J., \& Balázsi, C. (2010). Preparation and characterization of hydroxyapatite from eggshell. Ceramics International, 36(2), 803-806.

Khairil. 2012. Kerang (Anadara sp) Phylum Molluscahttp://biologikhairil.blogsp ot.com/2012/03/keranganadara-spphylum-mollusca.html, diakses tanggal 16 Maret 2018.

Ningsih, R. P., Wahyuni, N., \& Destiarti, L. 2014. Sintesis Hidroksiapatit dari Cangkang Kerang Kepah (Polymesoda Erosa) dengan Variasi Waktu Pengadukan. Jurnal Kimia Khatulistiwa, 3(1), 22-26.

Noor, A. F. M., Kasim, S. R., Othman, R., Ana, I. D., \& Ishikawa, K. 2013. Synthesis of biphasic calcium phosphate by hydrothermal route and conversion to porous sintered scaffold. Journal of Biomaterials and Nanobiotechnology, 4(3), 273 278.

Walendra. 2012. Sintesis dan karakterisasi hidroksiapatit berpori dari cangkang kerang darah. Tesis. Institut Pertanian Bogor. 